Arch. hist. jap. Vol. 18, n. 4 (Januar 1960).

S. $539-543$.

Anat. Inst. d. Med. Fak., Univ. Okayama (Vorstand: Prof. M. SEKI).

\title{
Über die Veränderungen der Bindegewebszellen im Gewebe unter der Epidermis, in welches die Eisenionen von außen durch die Schweißkanäle eingedrungen sind.
}

\author{
外から汗腺管を通って鉄イオンが進入した袁皮下組織の \\ 結織細胞の変化について。
}

Takanori OHARA 大原孝度.

(Eingegangen am 8. September 1959.)

Es wurde in meiner vorigen Arbeit (1959) festgestellt, daß beim langzeitigen Eintauchen der Pfote der Maus in einer konzentrierten Salzlösung die Salzionen durch die Schweißikanäle an der Fußsohle in das Bindegewebe unter der Epidermis eingehen können. Nach der Untersuchung von RIN (1959) können oxydierend wirkende Salzlösungen, wenn sie auf die äußere Haut des Rückens der Maus wirken, die Bindegewebszellen unter der Haut reizen und Fibrohistiocyten und Histiocyten zahlreich entstehen lassen. In manchen warmen Quellen in Japan sind Eisenionen reichlich enthalten. Wenn die Eisenionen durch die Schweißkanäle in das subepidermale Gewebe eingehen, so werden sie vielleicht auf die dort vorhandenen Bindegewebszellen reizend wirken. Die folgende Untersuchung wurde zur Bestätigung dieser Vermutung vorgenommen.

\section{Material und Methode.}

Es wurde eine 3.5\% ige Lösung von Ferrosulfat $\left(\mathrm{Fe} \mathrm{SO}_{4}\right.$ ) (von $\mathrm{pH} 4.6$ ) und eine 1.2\% ige Lösung von Ferrichlorid $\left(\mathrm{FeCl}_{3}\right.$ ) (von $\mathrm{pH} 3.0$ ) $38^{\circ} \mathrm{C}$ erwärmt, in welche man die Pfoten der Maus 1-3 Stunden lang eintauchte. 6 Stunden nach dem letzen Bad wurden die Tiere getötet, und die Fußsohle wurde ausgeschnitten und mit Formalinlösung 30 Minuten lang fixiert, daraus wurden Gefrierschnitte verfertigt. Nachdem man durch die TURNBULLblau- bzw. Berlinerblau-Reaktion das Eindringen der Eisenionen unter der Epidermis nachgewiesen hat, färbte man dieselben Schnitte nach der MÖLLENDORFFschen Einsenhämateinlackmethode und untersucht die Bindegewebszellen unter der Epidermis. Sicherheitshalber wurden bei jedem Versuch mehrere Mäuse benutzt. Dazu wurden noch Untersuchungen nach dem Eintauchen der Mäusepfoten in 1\%iger Eisensulfatlösung für 1 Stunde, in 10\%iger Eisensulfatlösung für 10 Minuten und in 10\%iger Eisenchloridlösung für 10 Minuten vorgenom. men. Man untersuchte manchmal außer Gefrierschnitten noch Celloidinschnitte.

In Japan gibt es im Gegensatz zu Europa nicht wenige warme Quellen von $\mathrm{pH}$ 3.0-4.6. Es gibt sogar warme Quellen von $\mathrm{pH} 1.5$ wie in Kusatsu (草津). Die Definition von VOGT (1940) über die Säuerlinge "Wässer, die reich sind an freiem Kohlendioxyd, wovon sie mehr als $1 \mathrm{~g}$ (im 1 Liter) enthalten" hat in Japan keine gültigkeit. 


\section{Ergebnisse.}

Vorerst sei das normale Bild des Gewcbes unter der Epidermis der Maus in Abb. 1 gezeigt. Nach dieser Färbungsmethode wird gezeigt, daß die meisten Fibrocyten dünne Fortsätze besitzen, so daß also das ganze Gewebe wie retikuläres Bindegewebe aussieht. Um das Zellenbild der fibrohistiocytären Gemeinschaft kurz auszudrücken, benutzt man nach der Einteilung von SEKI (1942) folgende Abkürzungen. Der FTypus (der fibrocytäre Typus) ist derjenige, in welchem die Fibrocyten 70-80\% aller Zellen ausmachen. Bei dem F'H-Typus (dem fibrohistiocytären Typus) kommen
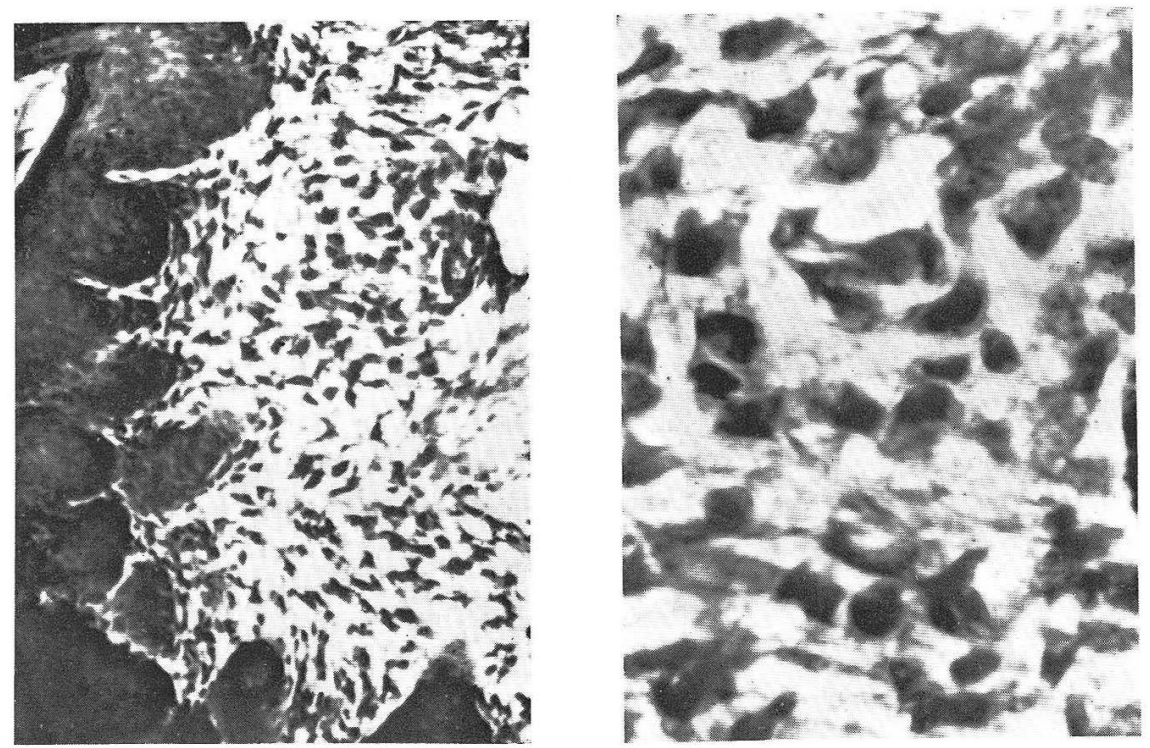

Abb. 1. A und B. Normales Gewebe unter der Epidermis des Sohlenballens der Maus. Färbung des Schnittes mit Eisenhämateinlack. $150 \times$ und $600 \times$.

die Fibrohistiocyten und Histiocyten am meisten vor, und zwar zu 50-50\% aller Zellen. Bei dem H-Typus (dem histiocytären Typus) sind die Histiocyten am meisten, und zwar zu 30-10\% aller Zellen. Das in Abb. 1 gezeigte normale Gewebe unter der Epidermis der Fußsohle gehört dem F-Typus an.

a) Bad in Ferrosulfat ( $\left.\mathrm{FeSO}_{4}\right)$-Lösung.

6 Stunden nach dem letzten Bad verkürzen die Fibrocyten im Gewebe unter der Epidermis, in welches die Eisenionen durch die Schweißkanäle eindrungen sind, ihre Fortsätze und wandeln sich in Fibrohistiocyten und ferner in abgerundete Histiocyten um (Abb. 2). Stellenweise entstehen recht zahlreiche Fibrohistiocyten und kleine Histiocyten, und das Zellenbild wird der FH-Typus.

b) Bad in Ferrichlorid ( $\left.\mathrm{FeCl}_{3}\right)$-Lösung.

Die Veränderungen der Fibrocyten ist weitaus stärker als beim Ferrosulfat. Sie ziehen ihre Fortsätze ein, und werden Fibrohistiocyten. Sie teilen sich aber auch amitotisch und liefern kleine Zellen. Daraus entstehen kleine Histiocy ten und mono- 

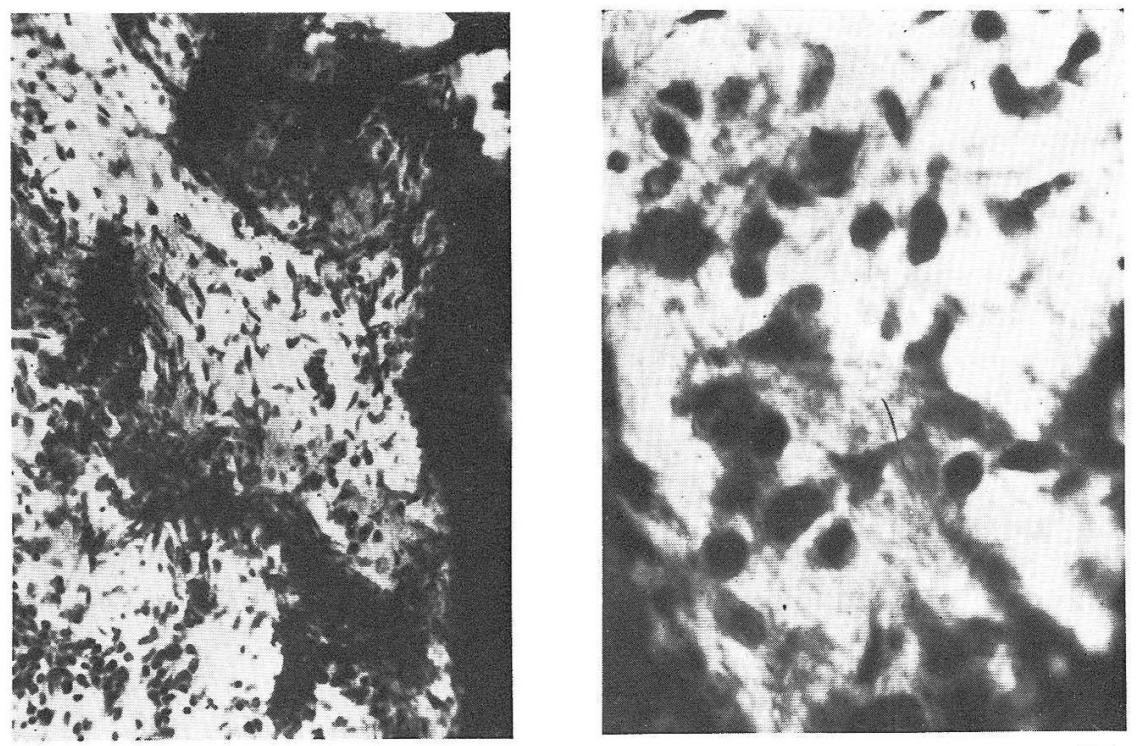

Abb. 2. A und B. 6 Stunden nach 3stündigem Bad in 3.5\% igem Ferrosulfat. Beachte Fibrocyten und ihre Abkömmlinge, Fibrohistiocyten und Histiocyten. $150 \times$ und $600 \times$

cytäre Formen. Das Bild des Gewebes wird nunmehr der FH-Typus oder H-Typus, oder aber es vermehren sich manchmal kleine Histiocyten und monocy täre Zellen sehr stark (Abb. 3).
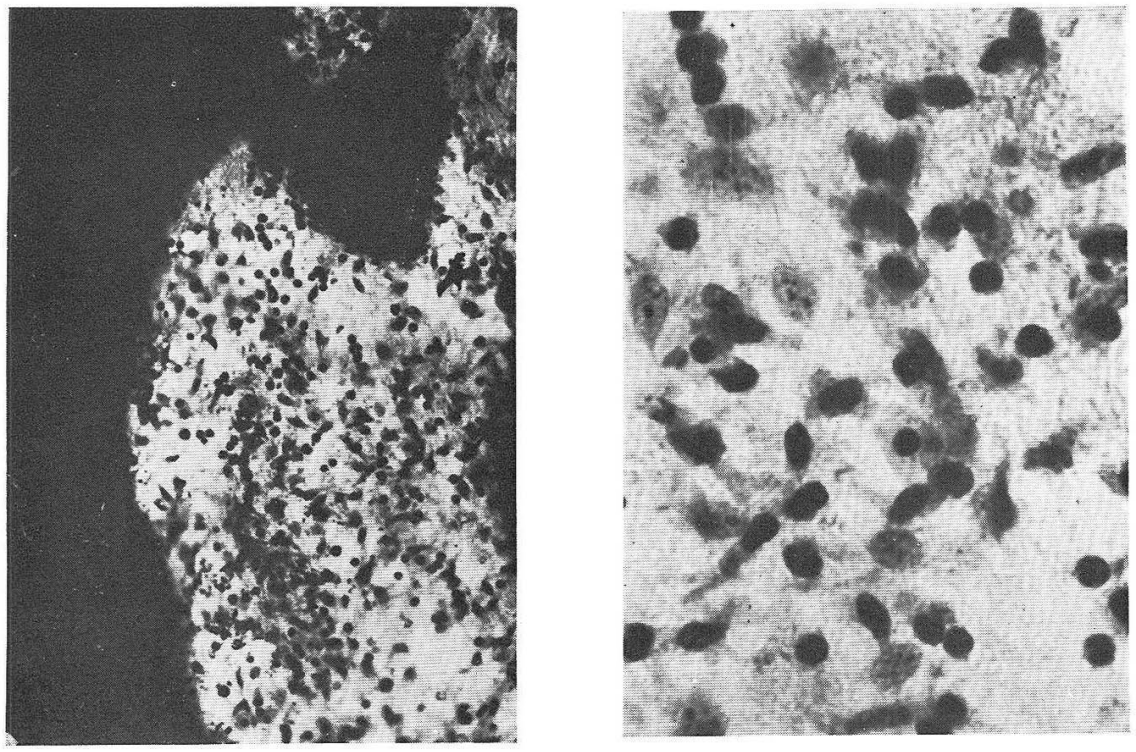

Abb. 3. A uud B. 6 Stunden nach 3stündigem Bad in 1.2\%igem Ferrichlorid. Vermehrte kleine Histiocyten und monocytäre Formen. $150 \times$ und $600 \times$ 
Bei der Maus gibt es auf der Körperoberfläche keine Schweißdrüsen mit Ausnahme von der Fußsohle. Beim Menschen finden sich die Mündungen der Schweißdrüsen auf dem ganzen Körper, und zwar, abgesehen vom Kopf und Hals, nach KO. YAMA (1934) etwa 3 Millionen Schweißdrüsenmündungen. (Haarbalgdrüsen sollen in den gleichen Körperteilen etwa 800 Tausende vorhanden sein.)

Wenn verschiedene Stoffe in warmen Quellen beim Bad durch so viele Schweißkanäle in das Körperinnere eindringen, so kann der Körper dadurch beträchtlich beeinflußt werden. In der Praxis sind nach dem Bad in stark sauren Quellen die Veränderungen der Haut am meisten augenscheinlich. Das sog. Zeitbad in Kusatsu (草津) ist bekannt, nach welchem man ein Bad in der warmen Quelle von $\mathrm{pH} 1.5$ und $45^{\circ}-47^{\circ} \mathrm{C}$ genau 3 Minuten nimmt, und zwar täglich 4 mal. Wenn man diese Badkur 1-2 Wochen fortsetzt, so erodiert die Haut. Das soll ein Zeichen von Heilung verschiedener chronischer Krankheiten sein. Nach KATO (1932) entsteht die Erosion am leichtesten an der Oberfläche des Scrotums, der großen Schamlippen, der Analgegend, der Leistengegend und der Achselhöhle u. a., deren Haut immer etwas feucht ist.

\section{Zusammenfassung.}

Wenn die Eisenionen von außen durch die Schweißkanäle an den Sohlenballen der Maus in das Bindegewebe unter der Epidermis eindringen, so werden die dort vorhandenen Bindegewebszellen gereizt und es vermehren sich Fibrohistiocyten und Histiocyten, manchmal auch monocytäre Formen. Die in dieser Untersuchung benutzten Eisensalzlösungen waren von $\mathrm{pH} 3.0$ bis 4.6, und die Mitwirkung der Waserstoffionen ist denkbar. Aber in Japan gibt es zur Kur angewandte warme Quellen von einem solchen $\mathrm{pH}$ und darüber nicht wenig.

\section{内 容 自 抄。}

鉄イオンが外から二十日鼠の足底球にある汗腺管を通って表皮下の結合組織に 大れば，その結合細胞を刺戟し，線維細胞を線組球と組織球へ転化せしめる.

その際に鉄イオン $\mathrm{pH}$ 濃度は 3.0 から 4.6 の間であったから，水素イオンの共 作用も考えられる。ただし日本の療養に用いられる温泉にはこの程度の $\mathrm{pH}$ とそ れ以上のあのが少なくないのである。

\section{Literatur.}

Ohara, T.: Beobachtung des Eintrittes von Eisenionen und sauren und basischen Farbstoffen von außen in die Schweißkanäle und darüber hinaus in die unter der Epidermis liegende lockere Bindegewebsschicht (an der Maus). Arch. Hist. jap. 18 (1959). — Rin, E.: Badwirkungen von oxydierenden und reduzierenden Substanzen auf die fibrohistiocytäre Zellgemeinschaft unter der Haut der Maus. - Kato, T.: Medizinische Beobachtung der Hauterosion an Gästen im Bad Kusatsu. (Jap.) Jissen-Igaku. 2 (1932). - Koyama, K.: Über die Verteilung der Schweißdrüsen bei den Japanern. Okajimas Fol. anat. jap. 15 (1937). 
- Seki, M.: Wirkung der Mineralbäder auf das fibrohistiocytäre System. I. Stark saure Quellen. Acta anat. nipp. 20 (142). — Vogt, H.: Lehrbuch der Bäder- und Klimaheilkunde. Berlin 1940. 